\title{
MTHFR polymorphisms in childhood acute lymphoblastic leukemia: influence on methotrexate therapy
}

This article was published in the following Dove Press journal:

Pharmacogenomics and Personalized Medicine

27 March 2017

Number of times this article has been viewed

\author{
Maitane Umerez' \\ Ángela Gutierrez-Camino' \\ Carmen Muñoz-Maldonado' \\ Idoia Martin-Guerrero' \\ Africa Garcia-Orad ${ }^{1,2}$ \\ 'Department of Genetics, Physical \\ Anthropology and Animal Physiology, \\ Faculty of Medicine and Nursery, \\ University of the Basque Country, \\ UPV/EHU, Leioa, ${ }^{2}$ BioCruces Health \\ Research Institute, Barakaldo, Spain
}

Correspondence: Africa Garcia-Orad Department of Genetics, Physical Anthropology and Animal Physiology, Faculty of Medicine and Nursery, University of the Basque Country, UPV/EHU, Barrio Sarriena s/n, 48940 Leioa, Spain

Tel +34946012909

Email africa.garciaorad@ehu.eus

\begin{abstract}
Methotrexate (MTX) is an important component in the therapy used to treat childhood acute lymphoblastic leukemia (ALL). Methylenetetrahydrofolate reductase (MTHFR) is a key enzyme for MTX pharmacokinetics. Two single-nucleotide polymorphisms in MTHFR gene, C677T and A1298C, affecting MTHFR activity, have been widely studied as potential markers of MTX toxicity and/or outcome in pediatric ALL. In this review, we show that the majority of published reports do not find association or present opposite effect. Therefore, MTHFR C677T and A1298C polymorphisms do not seem to be good markers of MTX-related toxicity and/or outcome in pediatric ALL. The efforts should be focused on other genes, such as transporter genes or microRNA-related genes.
\end{abstract}

Keywords: MTHFR, methotrexate, toxicity, outcome, C677T, A1298C

\section{Introduction}

Acute lymphoblastic leukemia (ALL) is the most common type of cancer in children, representing $\sim 30 \%$ of all childhood malignancies. ${ }^{1,2}$ Survival rates have increased dramatically over the last years because of chemotherapy progress, with expected cure rates higher than $80 \% .{ }^{3}$ Methotrexate (MTX) is an important drug used in the treatment protocols for ALL. However, MTX can cause toxicity, leading to a dose reduction or treatment interruption, which could compromise the survival.

MTX is a folate analog that enters the cell via active transport mediated by the reduced folate carrier (RFC1). ${ }^{4}$ Then, MTX inhibits dihydrofolate reductase, arresting the folic acid cycle and affecting other important enzymes such as methylenetetrahydrofolate reductase (MTHFR), an enzyme that interferes with nucleic acid synthesis and favors cell death. ${ }^{5}$ Thus, MTHFR is a key enzyme for intracellular folate homeostasis and metabolism, because it catalyzes the irreversible conversion of 5,10-methylenetetrahydrofolate, required for purine and thymidine synthesis, to 5-methyltetrahydrofolate, required for protein synthesis and nucleic acid methylation. Subsequently, changes in the activity of MTHFR provoking an impaired conversion of 5,10-methylenetetrahydrofolate to 5-methyltetrahydrofolate could modify folate pools and in turn alter the response of malignant and nonmalignant cells to MTX and influence its toxicity ${ }^{6}$ (Figure 1).

In this context, two of the MTHFR polymorphisms most widely studied in relation to the toxicity of MTX are C677T (causing Ala222Val) and A1298C (causing Glu429Ala). Both polymorphisms have been associated with reduced enzyme activity. In the case of C677T, 677CT and 677TT individuals exhibit $60 \%$ and $30 \%$ of the normal MTHFR 


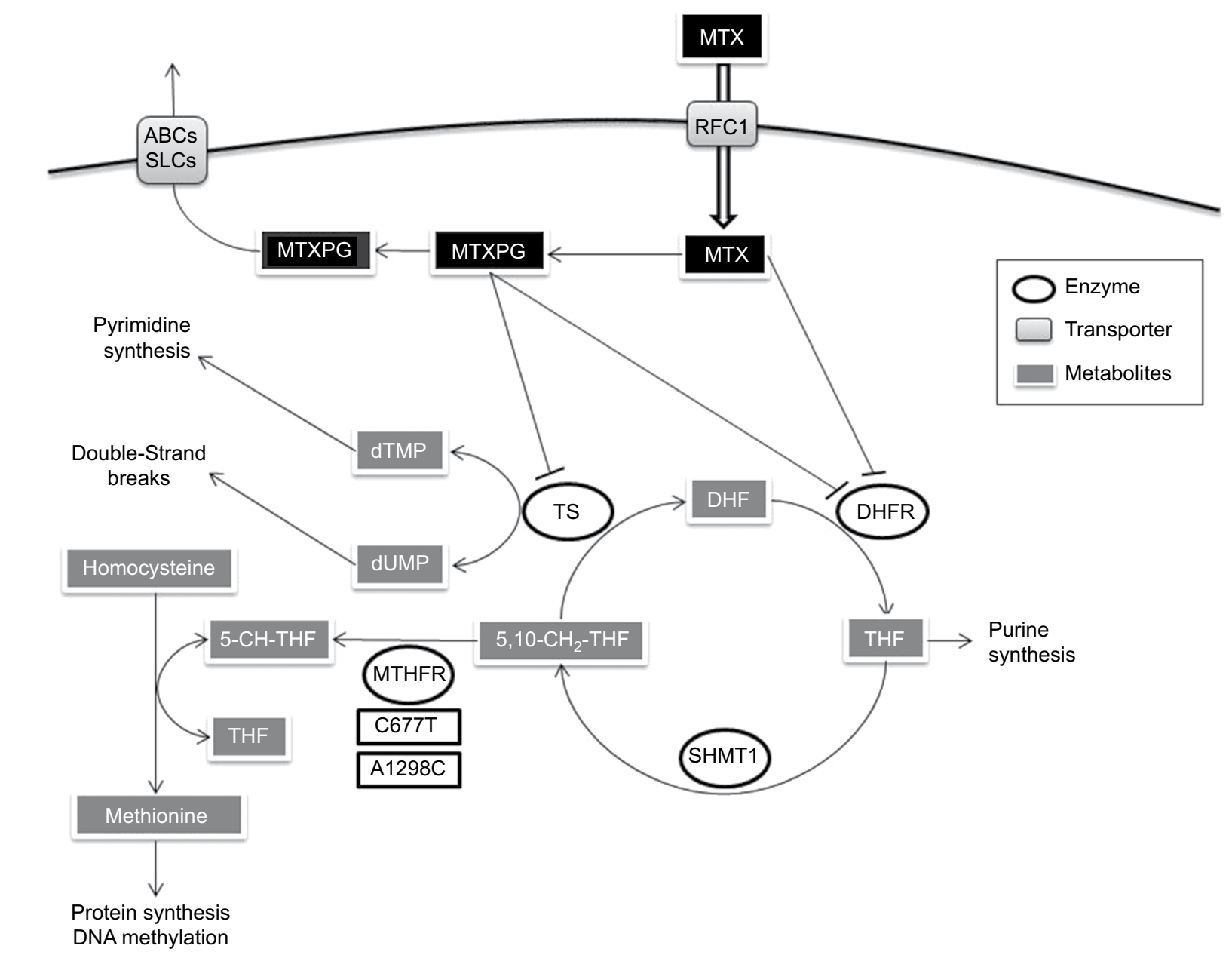

Figure I MTX pathway.

Note: MTX and its metabolites are indicated.

Abbreviations: ABCs, ABC family transporters; DHF, dihydrofolate; DHFR, dihydrofolate reductase; MTHFR, methylenetetrahydrofolate reductase; MTX, methotrexate; MTXPG, methotrexate polyglutamated forms; RFCI, reduced folate carrier; SHMTI, serine hydromethyl transferase; SLCs, SLC family transporters; THF, tetrahydrofolate; TS, thymidilate synthase; 5-CH-THF, 5-methyltetrahydrofolate; 5, 10-CH2-THF, 5, 10-methylenetetrahydrofolate.

activity, respectively. ${ }^{7,8}$ In the case of A1298C, $1298 \mathrm{CC}$ individuals show $60 \%$ of the normal activity. ${ }^{9}$ Therefore, the patients carrying the variant alleles might have a higher intolerance to MTX or an increased risk of progression. ${ }^{8}$

MTX intolerance can manifest through adverse reactions of several organ systems such as hematological (anemia, thrombocytopenia, leukopenia, neutropenia), gastrointestinal (mucositis), hepatobiliary, urogenital, or central nervous system. ${ }^{10}$ Also, MTX plasma levels are used as an objective MTX-related toxicity marker. ${ }^{11}$ In some patients, the toxic effects are so serious that the dose must be cut down or the treatment paused, which besides the problems related to toxicity, can also have a negative impact on survival. ${ }^{12}$

As we have mentioned herein, variants that alter MTHFR activity may increase the availability of 5,10-methylenetetrahydrofolate and decrease 5-methyltetrahydrofolate. The reduction of this last would lead to DNA hypomethylation, which could invoke carcinogenesis through three different mechanisms: chromosomal instability, reactivation of elements, and loss of imprinting. ${ }^{13}$ The loss of methylation might favor mitotic recombination, leading to loss of heterozygosity as well as promoting karyotypically detectable rearrangements. Intragenomic parasitic DNA and other previously silent transposons may then be transcribed and even "jump" to other parts of the genome, leading to disruption of normal genes. Hypomethylation can likewise affect imprinted genes, which have been shown to contribute to carcinogenesis. Finally, genomic DNA hypomethylation can also increase through all the tumorigenic steps ${ }^{14}$ from the benign proliferations to the invasive cancers. ${ }^{13}$ Therefore, decreased MTHFR activity due to $677 \mathrm{~T}$ or $1298 \mathrm{C}$ alleles could induce hypomethylation, and all these modifications can lead to an increase in carcinogenesis.

To date, several groups have investigated the potential role of MTHFR polymorphisms in relation to the toxicity of MTX, as well as outcome in pediatric ALL, but the 
conclusions remain controversial. Some studies do not find association, whereas others present opposite effect. In consequence, we consider that it would be interesting to clarify these discrepancies.

\section{Toxicity and MTHFR C677T and AI 298C polymorphisms}

In 2013, our group performed an exhaustive search to identify studies that examined the association between the C677T and A1298C polymorphisms of MTHFR and MTX toxicity in pediatric ALL patients. We used the keywords and subject terms "MTHFR and acute leukemia", and "MTHFR and polymorphism(s) and toxicity" to search PubMed (www. ncbi.nlm.nih.gov/pubmed) for articles published through November 2011. We also carried out a meta-analysis with those articles supplying enough information on toxicity by genotype. The study was performed in a population composed only of pediatric ALL patients for short-term toxic effects including (MTX plasma levels, mucositis, hepatic toxicity, neutropenia, thrombocytopenia, anemia, and leucopenia).

The meta-analysis included 24 studies for C677T and 16 studies for A1298C. For C677T, none of the analysis revealed a statistically significant association with toxicity. In the case of A1298C, only a slight protective effect of $1298 \mathrm{CC}$ genotype for leukopenia was observed. ${ }^{15}$ Therefore, we concluded that there was no evidence to support the use of either the MTHFR C677T or the A1298C single-nucleotide polymorphisms (SNPs) as MTX toxicity markers in pediatric ALL patients, and consequently the MTX dose should not be adjusted based on these variants.

At the same time, Yang et $\mathrm{al}^{16}$ performed another metaanalysis studying the effect of C677T and A1298C MTHFR polymorphisms on MTX-induced myelosuppression, oral mucositis, liver, hematological, gastrointestinal, and neurological toxicities. They only found a slight association between $\mathrm{C} 677 \mathrm{~T}$ and gastrointestinal toxicity in pediatric ALL. None of the polymorphisms was associated to any of the other studied toxicities, so again in this study, neither C667T nor A1298C were proved to be good toxicity markers for MTX dose reduction.

In spite of all this evidence, new studies are being published every year analyzing the involvement of MTHFR C677T and A1298C polymorphisms in MTX toxicity in pediatric ALL treatment. Herein, we have performed an exhaustive search to identify new studies that explore the association between the $\mathrm{C} 677 \mathrm{~T}$ and A1298C polymorphisms of MTHFR and MTX-induced toxicity from November 2011 to November 2016, following the same strategy as before. ${ }^{15}$
Keywords "MTHFR" and "acute lymphoblastic leukemia" for PubMed database were used.

The search provided 186 records, 114 of them were directly discarded because they were published before 2011 . From the remaining 72 papers, after abstract screening, 50 were excluded for not analyzing C677T and A1298C polymorphisms in pediatric ALL. For the other 22, full lecture was performed. Seven out of 22 articles were discarded, 4 because they were not focused on the analysis of C677T and A1298C polymorphism and MTX-induced toxicities, ${ }^{17-20}$ and other 3 because they analyzed the effect of the C677T/A1298C haplotype in MTX-related toxicity and each genotype could not be evaluated separately. ${ }^{21-23} \mathrm{We}$ finally reviewed 15 articles that analyzed the $M T H F R$ polymorphisms in relation to MTX-induced toxicities in pediatric ALL patients. Of the 15 reviewed papers, 2 were discarded for analyzing only outcome, and 13 studies that analyzed the association with MTX induced toxicities remained. The search and study selection process are shown in Figure 2.

\section{C677T polymorphism analysis}

The 13 selected articles analyzed the C677T polymorphism in relation to MTX-induced toxicities. From them, only 5 found significant associations with toxicity, but with contradictory results: 2 studies related the $\mathrm{T}$ variant allele to a decrease in toxicity risk, ${ }^{24,25}$ whereas the other 3 associated it to increased risk (Table 1). ${ }^{26-28}$

When we analyzed those studies in depth, we again found discordant results (Table 2). The association study between MTX pharmacokinetics and C677T polymorphism showed that 7 out of 8 studies did not find significant association. Haase et $\mathrm{al}^{25}$ was the only study in which MTX levels were significantly increased in patients with the MTHFR C677T wild type compared to CT/TT genotype variant carriers. However, the number of patients included in this study was very low $(n=35)$. In our previous meta-analysis, only one study found association, but the result was just the opposite. ${ }^{29}$ Until now, taking into account our previous meta-analysis and the studies included in this review, a total of 13 studies have been performed about MTX pharmacokinetics, 11 with no association, and 2 with association but with opposite results. Therefore, C677T could not be considered as a good marker for MTX pharmacokinetics.

With regard to hematological toxicity, when anemia was analyzed, only 2 out of 5 studies found association. Haase et $\mathrm{al}^{25}$ showed that the variant of C677T was associated with a decreased toxicity, whereas Zgheib et $\mathrm{al}^{27}$ found the opposite effect. The other 3 studies found no association with anemia 


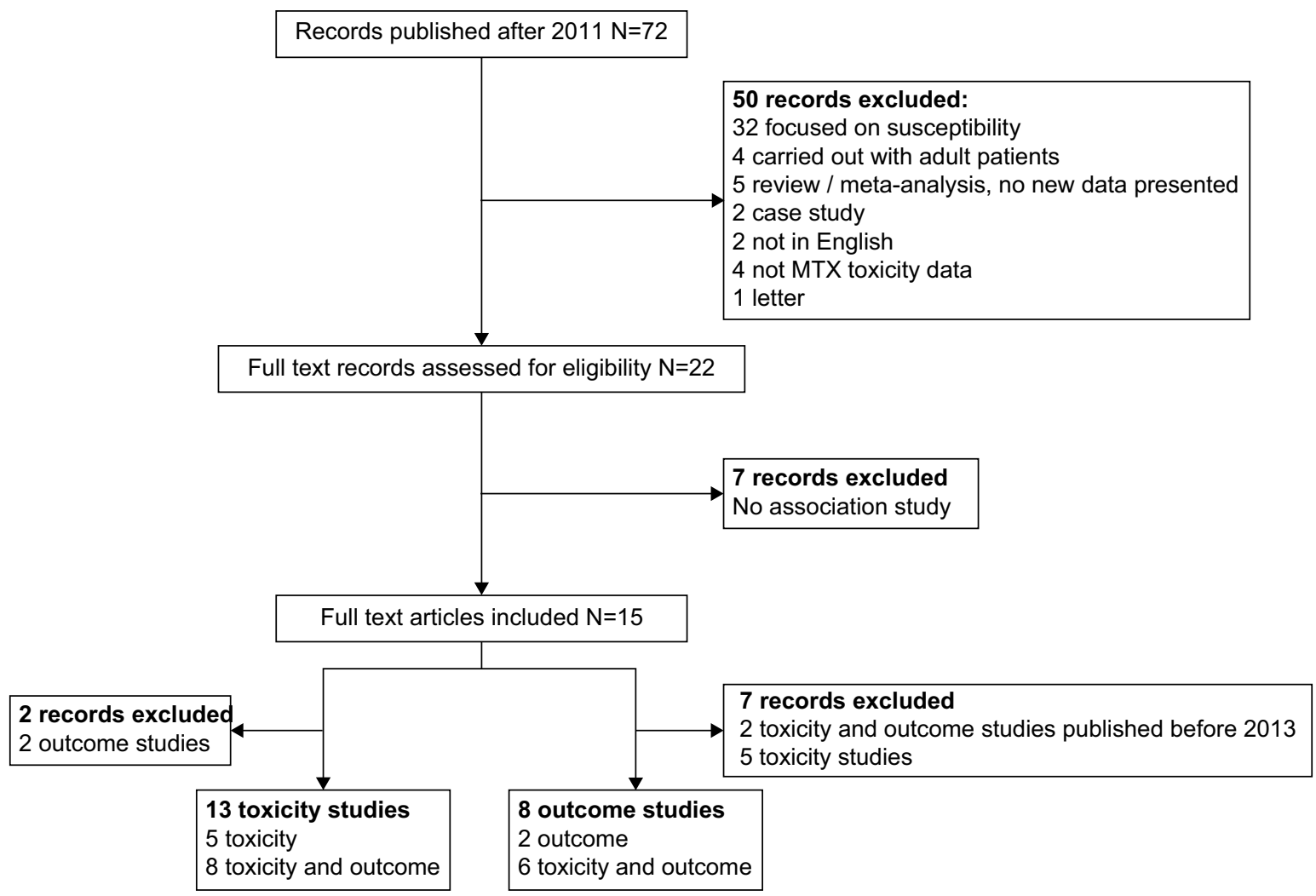

Figure 2 Flow diagram of study selection.

Abbreviation: MTX, methotrexate.

Table I List of I 3 studies that analyzed association between the MTHFR C677T polymorphism and MTX toxicity in pediatric ALL, grouped according to the level of association between the SNP and MTX toxicity

\begin{tabular}{|c|c|c|c|c|}
\hline \multicolumn{5}{|c|}{ MTHFR C677T } \\
\hline $\begin{array}{l}\text { Patient } \\
\text { population }\end{array}$ & $\begin{array}{l}\text { MTX } \\
\text { dose }\end{array}$ & Population & $\begin{array}{l}\text { Association } \\
\text { with toxicity }\end{array}$ & Reference, year \\
\hline $21 \mathrm{ALL}^{\mathrm{C}}$ & High & Indian & NA & Moulik et al, ${ }^{31} 2016$ \\
\hline \multirow{2}{*}{$106 \mathrm{ALL}^{\mathrm{C}}$} & & & NA & Yazıcıoğlu et al, ${ }^{32}$ \\
\hline & High & Turkish & & 2016 \\
\hline $56 \mathrm{ALL}$ or & & & NA & Tsujimoto et al, ${ }^{47}$ \\
\hline Lymphoma A & High & Japanese & & 2016 \\
\hline $53 \mathrm{ALL}^{\mathrm{A}}$ & Low & Japanese & NA & Suzuki et al, ${ }^{30} 2015$ \\
\hline $91 \mathrm{ALL}^{\mathrm{C}}$ & High & Chinese & NA & Wang et al, ${ }^{48} 2014$ \\
\hline $499 \mathrm{ALL}^{\mathrm{A}}$ & High & German & NA & Radtke et al, ${ }^{39} 2013$ \\
\hline $18 \mathrm{ALL}^{\mathrm{C}}$ & High & Brazilian & NA & de Deus et $a l,{ }^{49} 2012$ \\
\hline $100 \mathrm{ALL}^{\mathrm{A}}$ & ND & Korean & NA & Kim et al,,$^{50} 2012$ \\
\hline \multirow{2}{*}{$109 \mathrm{ALL}^{\mathrm{C}}$} & & & $-\mathrm{T}$ & Ramírez-Pacheco \\
\hline & High & Mexican & & et al, ${ }^{24} 2016$ \\
\hline $35 \mathrm{ALL}^{\mathrm{B}}$ & High & Caucasian & $-\mathrm{T}$ & Haase et al, ${ }^{25} 2012$ \\
\hline $161 \mathrm{ALL}^{\mathrm{C}}$ & High & Argentinian & $+\mathrm{T}$ & Aráoz et al, ${ }^{26} 2015$ \\
\hline $127 \mathrm{ALL}^{\mathrm{C}}$ & High & Lebanese & $+\mathrm{T}$ & Zgheib et al, ${ }^{27} 2014$ \\
\hline $103 \mathrm{ALL}$ and & & & $+\mathrm{T}$ & Fukushima et $\mathrm{al}^{28}$ \\
\hline $\mathrm{NHL}^{\mathrm{A}}$ & High & Japanese & & 2013 \\
\hline
\end{tabular}

Notes: Type of sample: A, normal; B, tumor; C, unknown. High MTX dose $=1.5-5$ $\mathrm{g} \mathrm{m}^{-2}$; Low MTX dose $=25 \mathrm{mg} \mathrm{m}^{-2}$.

Abbreviations: MTHFR, methylenetetrahydrofolate reductase; SNP, single-nucleotide polymorphism; MTX, methotrexate; ALL, acute lymphoblastic leukemia; NHL, nonHodgkin Lymphoma; ND, no data; NA, no association between SNP and toxicity; +T, SNP is associated with increased toxicity; $-\mathrm{T}, \mathrm{SNP}$ is associated with decreased toxicity.
(Table 2). Contradictory results were also seen for leukopenia, for which Haase et $\mathrm{al}^{25}$ showed that the C677T T variant allele was associated with a decreased toxicity, whereas Aráoz et a ${ }^{26}$ found that this allele increased the risk of severe leukopenia, but only in carriers who received $2 \mathrm{~g} / \mathrm{m}^{2}$ of MTX. However, Aráoz et $\mathrm{a}^{26}$ also observed that the $677 \mathrm{~T}$ allele did not seem to modulate the presence of severe adverse events in patients who received $5 \mathrm{~g} / \mathrm{m}^{2}$ of MTX. The analysis of leukopenia in the other 3 studies showed no association with toxicity (Table 2). Neutropenia was analyzed in 4 studies. Only the study of Aráoz et a ${ }^{26}$ found risk $677 \mathrm{~T}$ allele associated to neutropenia in patients who received low doses of MTX $\left(2 \mathrm{~g} / \mathrm{m}^{2}\right)$. None of the other 3 studies found association. Again, these results are in line with the results of our previous meta-analysis in which we proposed that C677T polymorphism does not seem to be a good marker for hematological toxicity.

Hepatotoxicity was analyzed in 7 studies, and only the study of Fukushima et $\mathrm{al}^{28}$ found significant association for $677 \mathrm{CT} / \mathrm{TT}$ carriers. This study was conducted in a cohort of 103 Japanese patients, that mixed ALL $(n=82)$ and nonHodgkin lymphoma (NHL) (N=21) patients. In contrast, another study carried out in another Japanese population found no significant association. ${ }^{30}$ The other 5 studies performed in other populations found no significant association 
Table 2 Types of toxicities analyzed and the findings in each study of the association between the MTHFR C677T polymorphism and MTX toxicity

\begin{tabular}{|c|c|c|c|c|c|c|c|c|c|c|}
\hline \multicolumn{11}{|c|}{ MTHFR C677T } \\
\hline \multirow{2}{*}{$\begin{array}{l}\text { Reference, } \\
\text { year }\end{array}$} & \multirow{2}{*}{$\begin{array}{l}\text { MTX } \\
\text { kinetics }\end{array}$} & \multicolumn{4}{|c|}{ Hematologic toxicity } & \multirow{2}{*}{$\begin{array}{l}\text { Hepatic } \\
\text { toxicity }\end{array}$} & \multirow[t]{2}{*}{ Mucositis } & \multirow{2}{*}{$\begin{array}{l}\text { Renal } \\
\text { toxicity }\end{array}$} & \multirow[t]{2}{*}{ Neurotoxicity } & \multirow[t]{2}{*}{ Other } \\
\hline & & Anemia & Thrombocytopenia & Leukopenia & Neutropenia & & & & & \\
\hline $\begin{array}{l}\text { Moulik } \\
\text { et al, } 2016\end{array}$ & - & NA & NA & - & NA & NA & NA & NA & - & $N A^{a, b}$ \\
\hline $\begin{array}{l}\text { Yazıcıoğlu } \\
\text { et al, }{ }^{32} 2016\end{array}$ & $\mathrm{NA}^{\mathrm{c}}$ & NA & NA & NA & NA & NA & NA & NA & NA & - \\
\hline $\begin{array}{l}\text { Tsujimoto } \\
\text { et al, }{ }^{47} 2016\end{array}$ & - & - & - & - & - & - & - & - & NA & - \\
\hline $\begin{array}{l}\text { Suzuki et al, }{ }^{30} \\
2015\end{array}$ & - & - & - & NA & - & NA & - & - & - & $\mathrm{NA}^{\mathrm{b}}$ \\
\hline $\begin{array}{l}\text { Wang et al, }{ }^{48} \\
2014\end{array}$ & $N A^{d, e}$ & - & - & - & - & - & - & - & - & - \\
\hline $\begin{array}{l}\text { Radtke } \\
\text { et al },^{39} 2013\end{array}$ & $N A^{\mathrm{fg}, \mathrm{h}}$ & - & - & - & - & - & NA & - & - & - \\
\hline $\begin{array}{l}\text { de Deus } \\
\text { et al, }{ }^{49} 2012\end{array}$ & $N^{c}$ & - & - & - & - & NA & - & NA & - & - \\
\hline $\begin{array}{l}\text { Kim et al, }{ }^{50} \\
2012\end{array}$ & - & - & - & - & - & NA & - & - & - & $N A^{b, i}$ \\
\hline $\begin{array}{l}\text { Ramírez- } \\
\text { Pacheco } \\
\text { et al, }{ }^{24} 2016\end{array}$ & $N^{c}{ }^{c}$ & - & - & NA & - & - & $-\mathrm{T}$ & - & - & - \\
\hline $\begin{array}{l}\text { Haase et al, }{ }^{25} \\
2012\end{array}$ & $-T^{c}$ & $-T$ & - & $-\mathrm{T}$ & - & - & - & - & - & $-\mathrm{T}^{\mathrm{i}}$ \\
\hline $\begin{array}{l}\text { Aráoz et al, }{ }^{26} \\
2015\end{array}$ & - & NA & NA & $+\mathrm{T}$ & $+\mathrm{T}$ & NA & NA & - & - & - \\
\hline $\begin{array}{l}\text { Zgheib } \\
\text { et al, }{ }^{27} 2014\end{array}$ & $N A^{f, g, k}$ & $+\mathrm{T}$ & - & - & NA & - & - & - & - & $N A^{b}$ \\
\hline $\begin{array}{l}\text { Fukushima } \\
\text { et al, }{ }^{28} 2013\end{array}$ & $\mathrm{NA}^{\mathrm{c}}$ & - & - & - & - & $+\mathrm{T}$ & - & - & - & $+\mathrm{T}^{\mathrm{I}}$ \\
\hline
\end{tabular}

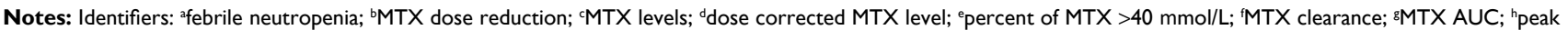
MTX plasma level; 'sepsis; 'rate of cycles with infection; 'time to reach MTX level <0,I mmol/L; 'MTX administration delay; -, not evaluated.

Abbreviations: MTHFR, methylenetetrahydrofolate reductase; SNP, single-nucleotide polymorphism; MTX, methotrexate; NA, no association between SNP and toxicity; $+\mathrm{T}$, SNP is associated with increased toxicity; $-\mathrm{T}$, SNP is associated with decreased toxicity.

either. Once more, these results are in line with the results found by our group in the previous review, in which 13 studies out of 16 were not significant.

Mucositis was analyzed in 5 studies, and only RamírezPacheco et $\mathrm{al}^{24}$ concluded that $\mathrm{CC}$ genotype was associated with a higher risk of developing mucositis in a cohort of 109 children with ALL. The rest of the 4 studies found no association, in line with our meta-analysis results in which 8 out of 10 studies were not significant.

Finally, for thrombocytopenia and renal toxicity with 3 studies and neurotoxicity with 2 studies, none of them found significant association. Once more, these results were in agreement with the previous ones.

In conclusion, after analyzing thoroughly a total of 37 articles and 4,583 patients (24 studies with 3,104 patients from the previous meta-analysis and 13 studies with 1,479 patients from our actual review) and considering that the majority of studies were not significant, the significant results were often contradictory or with low statistical power, we can conclude that C677T is not a good MTX toxicity marker in pediatric ALL.

\section{A I 298C polymorphism analysis}

Of the 13 articles reviewed, 10 analyzed the association of A1298C polymorphism with MTX-induced toxicity (Table 3). From them, only 3 studies found significant association. Moulik et $\mathrm{al}^{31}$ and Haase et $\mathrm{al}^{25}$ showed the $\mathrm{C}$ variant allele favoring an increase in toxicity, whereas Fukushima et $\mathrm{a}^{28}$ showed a protective role for the $\mathrm{C}$ variant allele. When the different toxicities were considered, almost all the results found no significant associations (Table 4).

Regarding anemia, 3 of 5 studies found no significant results, whereas both Moulik et $\mathrm{a}^{31}$ and Haase et $\mathrm{a}^{25}$ found association with an increase in toxicity for patients carrying 
Table 3 List of 10 studies that analyzed association between the MTHFR AI298C polymorphism and MTX toxicity in pediatric ALL, grouped according to the level of association between the SNP and MTX toxicity

\begin{tabular}{|c|c|c|c|c|}
\hline \multicolumn{5}{|c|}{ MTHFR AI 298C } \\
\hline $\begin{array}{l}\text { Patient } \\
\text { population }\end{array}$ & $\begin{array}{l}\text { MTX } \\
\text { dose }\end{array}$ & Population & $\begin{array}{l}\text { Association } \\
\text { with toxicity }\end{array}$ & Reference, year \\
\hline $106 \mathrm{ALL}^{\mathrm{C}}$ & High & Turkish & NA & $\begin{array}{l}\text { Yazıcıoğlu et al, }{ }^{32} \\
2016\end{array}$ \\
\hline $53 \mathrm{ALL}^{\mathrm{A}}$ & Low & Japanese & NA & Suzuki et al, ${ }^{30} 2015$ \\
\hline $161 \mathrm{ALL}^{\mathrm{C}}$ & High & Argentinian & NA & Aráoz et al, ${ }^{26} 2015$ \\
\hline I $27 \mathrm{ALL}^{\mathrm{C}}$ & High & Lebanese & NA & Zgheib et al, ${ }^{27} 2014$ \\
\hline 499 ALLA $^{A}$ & High & German & NA & Radtke et al, ${ }^{39} 2013$ \\
\hline $18 \mathrm{ALL}^{\mathrm{C}}$ & High & Brazilian & NA & de Deus et al, ${ }^{49} 2012$ \\
\hline $100 \mathrm{ALL}^{\mathrm{A}}$ & ND & Korean & NA & Kim et al,,$^{50} 2012$ \\
\hline $103 \mathrm{ALL}$ and & High & Japanese & $-\mathrm{T}$ & Fukushima et al, ${ }^{28}$ \\
\hline $\mathrm{NHL}^{\mathrm{A}}$ & & & & 2013 \\
\hline $21 \mathrm{ALL}^{\mathrm{C}}$ & High & Indian & $+\mathrm{T}$ & Moulik et al, ${ }^{31} 2016$ \\
\hline $35 \mathrm{ALL}^{\mathrm{B}}$ & High & Caucasian & $+\mathrm{T}$ & Haase et al, ${ }^{25} 2012$ \\
\hline
\end{tabular}

Notes: Type of sample: A, normal; B, tumor; C unknown. High MTX dose $=1.5-5 \mathrm{~g}$ $\mathrm{m}^{-2}$; Low MTX dose $=25 \mathrm{mg} \mathrm{m}^{-2}$.

Abbreviations: MTHFR, methylenetetrahydrofolate reductase; SNP, single-nucleotide polymorphism; MTX, methotrexate; ALL, acute lymphoblastic leukemia; NHL, nonHodgkin Lymphoma; ND, no data; NA, no association between SNP and toxicity; $+T$, SNP is associated with increased toxicity; $-\mathrm{T}, \mathrm{SNP}$ is associated with decreased toxicity.

the CC genotype. These studies included a low number of patients ( $n=21$ and $n=35$, respectively), whereas the studies that did not result in significance were performed in cohorts of $106,{ }^{32} 161,{ }^{26}$ and $127^{27}$ patients. Since our previous review found no association in 5 of the 6 studies that analyzed anemia and the one that showed association was performed in a population of 37 patients, ${ }^{33}$ we can conclude that A1298C variant is not a good marker for anemia.

Hepatotoxicity was analyzed in 7 studies, only Fukushima et $\mathrm{al}^{28}$ showed significant results in their cohort of children, which as previously mentioned, mixed 82 ALL patients and 21 NHL patients. In this study, 1298CC genotype patients presented a lower hepatic toxicity risk comparing to the 1298AA genotype patients. The other 6 studies did not find association between the polymorphism and hepatic toxicity. These results agree with our previous meta-analysis where 8 out of 10 studies neither found significant association. Moreover, the 2 studies that showed association in the previous meta-analysis found the opposite effect for the variant $\mathrm{C}$ allele that increased hepatic toxicity. ${ }^{33,34}$

For MTX pharmacokinetics and A1298C since November 2011, 6 new studies have been performed, but significant results have not been detected in any of them. These results in combination with the results from our previous meta-analysis, where only one study conducted in a population of 37 patients obtained significant results, ${ }^{33}$ give us a total confirmation of no association between the A1298C polymorphism and MTX pharmacokinetics.
None of the other analyzed toxicities (leukopenia, neutropenia, and mucositis with 4 studies; thrombocytopenia and renal toxicity with 3 studies; and neurotoxicity with 1 study) showed statistically significant results (Table 4).

The results from 26 articles and 3,546 patients (16 studies with 2,323 patients from the previous meta-analysis and 10 studies with 1,223 patients from our actual review) makes us reject the MTHFR A1298C polymorphism as a MTX toxicity marker.

To sum up, in these 13 new studies analyzing C677T and A1298C and MTX-induced toxicities, we have confirmed our previous results. Most of the studies concluded that there was no association between MTHFR polymorphisms and MTX toxicity, and in those few studies with positive associations, opposite effects were often observed. Therefore, we consider that MTHFR C677T and A1298C polymorphisms are not good toxicity markers in pediatric ALL, and we think that no further studies are needed in this line.

\section{Outcome and MTHFR C677T and AI 298C polymorphisms}

In 2014 , He et $\mathrm{al}^{35}$ published the results of a meta-analysis that studied the relationship between the MTHFR C677T and A1298C polymorphisms and ALL relapse risk. They conducted a literature search of PubMed (www.ncbi.nlm.nih.gov/pubmed) and Web of Knowledge (http://isiknowledge.com/) using the following keywords and subject terms: "acute lymphoblastic leukemia and relapse and polymorphism (variant)" and "methylenetetrahydrofolate reductase (MTHFR) and acute lymphoblastic leukemia and relapse", last updated on September 2013. The association between the two SNPs and ALL relapse was evaluated in childhood ALL patients. In He et al's ${ }^{35}$ work, the meta-analysis for childhood ALL was performed with 6 studies for C677T $(n=1,553)$ and with 3 studies for A1298C $(n=711)$. Significant association was only found for C677T. According to their results, the relapse risk in pediatric ALL was higher for the 677TT genotype than for the CT/CC genotypes.

Simultaneously, Ojha and Gurney ${ }^{36}$ published a systematic review on the association between MTHFR C677T and overall survival in pediatric ALL $(n=909)$. The search included literature through March 2013, and the review was based on 6 studies, 3 of them already included on He et al' s, ${ }^{35}$ meta-analysis. As expected, they reached a similar conclusion, individuals with MTHFR 677T variant showed a higher relative risk of pediatric ALL mortality, with greater statistical support for the genotype MTHFR 677TT.

Herein, we performed a new review of the literature published after the mentioned two reviews, from September 2013 to November 2016, to assess the relationship between 


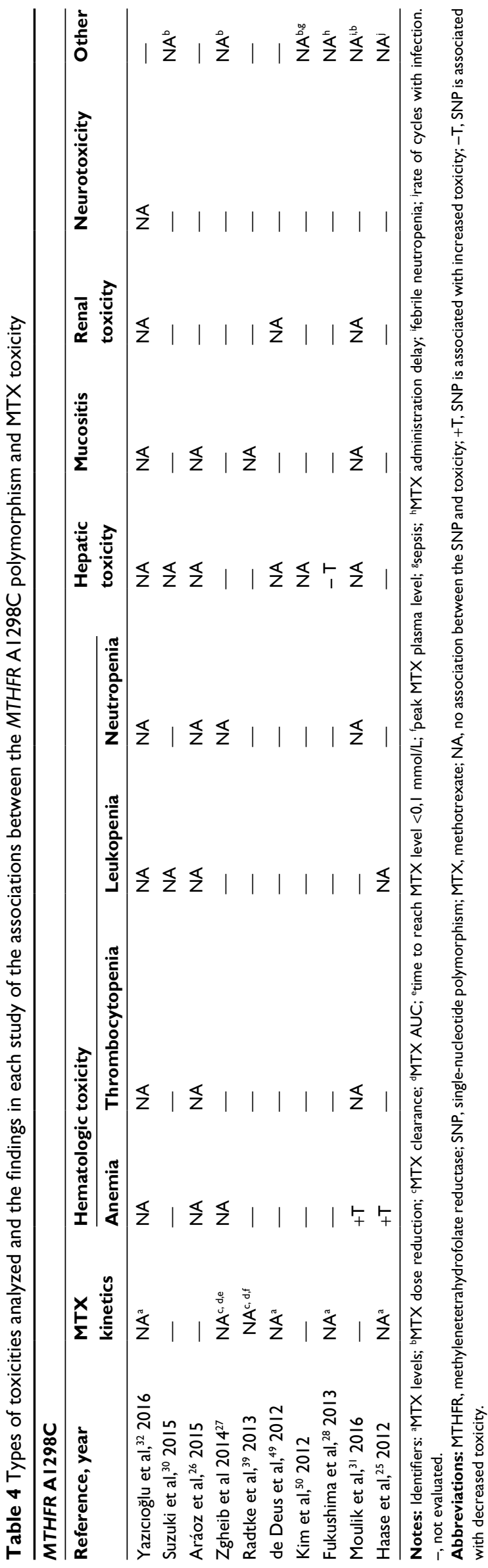

childhood ALL outcome and MTHFR C677T and A1298C polymorphisms. Keywords "MTHFR" and "acute lymphoblastic leukemia" for PubMed database were used.

The study selection process, previously described for toxicity studies, was the same for outcome in the first steps. Out of the 15 articles selected for complete lecture, 7 were discarded, 2 for being published before 2013 and 5 for not studying outcome. Finally, we analyzed 8 articles that studied the MTHFR polymorphisms in relation to pediatric ALL patients outcome (Figure 2).

\section{C677T polymorphism analysis}

From 2013, eight studies that included 1,353 pediatric ALL patients have analyzed the association between the C677T polymorphism and outcome (relapse, death, or secondary malignancy). None of the new eight studies showed significant association between outcome and C677T variant (Table 5). These results differ from the previously mentioned reviews that found association between increased relapse/ mortality risk and 677TT genotype. Nevertheless, in the He et al's, ${ }^{35}$ meta-analysis, the significant result is based only in two studies (D'Angelo et $\mathrm{a}^{37}$ and Tantawy et $\mathrm{al}^{38}$ ) from the 6 studies included. Taking all these results in consideration, we cannot affirm that MTHFR C677T polymorphism is a good outcome marker for pediatric ALL.

\section{A I298C polymorphism analysis}

In the case of A1298C, six new studies that included 1,104 pediatric ALL patients analyzed the association with outcome (relapse, death, or secondary malignancy). From them, 2 studies showed significant results but with opposite effect. Fukushima et a ${ }^{28}$ demonstrated that individuals with AC-CC genotypes presented increased Event Free Survival (EFS) (versus AA genotype), whereas Radtke et al's ${ }^{39}$ study found that individuals with $\mathrm{AC}$ or $\mathrm{CC}$ genotypes showed decreased EFS (versus AA genotype) (Table 6). The other 4 studies showed no association between A1298C and outcome, which is in line with the previously published meta-analysis of $\mathrm{He}$ et $\mathrm{al}^{35}$ and other 3 studies. All these results together suggest that MTHFR A1298C polymorphism is not a good predictor for outcome in childhood ALL.

In conclusion, our review indicates that MTHFR C677T and A1298C polymorphisms cannot be considered as outcome markers for childhood ALL.

\section{Conclusion}

Numerous studies have been performed analyzing the relationship between the C677T and A1298C polymorphisms of MTHFR and MTX toxicity and/or outcome in pediatric 
Table 5 List of 8 studies that analyzed association between the MTHFR C677T polymorphism and outcome

\begin{tabular}{|c|c|c|c|c|c|}
\hline \multicolumn{6}{|l|}{ MTHFR C677T } \\
\hline Patient population & MTX dose & Population & $\begin{array}{l}\text { Association with } \\
\text { outcome }\end{array}$ & Analyzed event & Reference, year \\
\hline $140 \mathrm{ALL}^{\mathrm{A}}$ & High & Argentinian & NA & $\mathrm{EFS}^{\mathrm{a}}$ & Leonardi et al, ${ }^{51} 2016$ \\
\hline $109 \mathrm{ALL}^{\mathrm{C}}$ & High & Mexican & NA & Relapse & Ramírez-Pacheco et al, ${ }^{24} 2016$ \\
\hline $106 \mathrm{ALL}^{\mathrm{C}}$ & High & Turkish & NA & $\mathrm{EFS}^{\mathrm{b}}$ & Yazıcıoğlu et al, ${ }^{32} 2016$ \\
\hline $202 \mathrm{ALL}^{\mathrm{C}}$ & High & Argentinian & NA & $\mathrm{EFS}^{\mathrm{c}}$ & Aráoz et al, ${ }^{26} 2015$ \\
\hline $94 \mathrm{ALL} / / 4 \mathrm{I} A L^{\mathrm{C}}$ & High & Caucasian/Vietnamese & NA & $\mathrm{EFS}^{\mathrm{a}}$ & Hoang et al, ${ }^{52} 2015$ \\
\hline $103 \mathrm{ALL}$ and $\mathrm{NHL}^{\mathrm{A}}$ & High & Japanese & NA & $\mathrm{EFS}^{\mathrm{b}}$ & Fukushima et al, ${ }^{28} 2013$ \\
\hline $499 \mathrm{ALL}^{\mathrm{A}}$ & High & German & NA & $\mathrm{EFS}^{\mathrm{c}}$ & Radtke et al, ${ }^{39} 2013$ \\
\hline $53 \mathrm{ALL}^{\mathrm{A}}$ & Low & Japanese & NA & Relapse & Suzuki et al, ${ }^{30} 2015$ \\
\hline
\end{tabular}

Notes: Type of sample: A, normal; C, unknown. High MTX dose $=1.5-5 \mathrm{~g} \mathrm{~m}^{-2}$; Low MTX dose $=25 \mathrm{mg} \mathrm{m}^{-2}$. Identifiers: ${ }^{2}$ event defined as relapse; bevent defined as relapse/ death; 'event defined as relapse/death/secondary malignancies.

Abbreviations: MTHFR, methylenetetrahydrofolate reductase; SNP, single-nucleotide polymorphism; MTX, methotrexate; ALL, acute lymphoblastic leukemia; NHL, nonHodgkin Lymphoma; NA, no association between the SNP and outcome; EFS, event free survival.

Table 6 List of 6 studies that analyzed association between the MTHFR AI298C polymorphism and outcome

\begin{tabular}{|c|c|c|c|c|c|}
\hline \multicolumn{6}{|l|}{ MTHFR AI 298C } \\
\hline Patient population & MTX dose & Population & $\begin{array}{l}\text { Association } \\
\text { with outcome }\end{array}$ & Analyzed event & Reference, year \\
\hline $106 \mathrm{ALL}^{\mathrm{C}}$ & High & Turkish & NA & $\mathrm{EFS}^{\mathrm{a}}$ & Yazıcıoğlu et al, ${ }^{32} 2016$ \\
\hline $202 \mathrm{ALL}^{\mathrm{C}}$ & High & Argentinian & NA & $\mathrm{EFS}^{\mathrm{b}}$ & Aráoz et al, ${ }^{26} 2015$ \\
\hline $94 \mathrm{ALL} / / 41 \mathrm{ALL}{ }^{\mathrm{C}}$ & High & $\begin{array}{l}\text { Caucasian/ } \\
\text { Vietnamese }\end{array}$ & NA & $\mathrm{EFS}^{\mathrm{c}}$ & Hoang et al, ${ }^{52} 2015$ \\
\hline $53 \mathrm{ALL}^{\mathrm{A}}$ & Low & Japanese & NA & Relapse & Suzuki et al, ${ }^{30} 2015$ \\
\hline $499 \mathrm{ALL}^{\mathrm{A}}$ & High & German & $-\mathrm{AS}$ & $\mathrm{EFS}^{\mathrm{c}}$ & Radtke et al, ${ }^{39} 2013$ \\
\hline $103 \mathrm{ALL}$ and $\mathrm{NHL}^{\mathrm{A}}$ & High & Japanese & $+\mathrm{AS}$ & $\mathrm{EFS}^{\mathrm{b}}$ & Fukushima et al, ${ }^{28} 2013$ \\
\hline
\end{tabular}

Notes: Type of sample: A, normal; C, unknown. High MTX dose $=1.5-5 \mathrm{~g} \mathrm{~m}^{-2}$; Low MTX dose $=25 \mathrm{mg} \mathrm{m}^{-2}$. Identifiers: ${ }^{\mathrm{a} e v e n t}$ defined as relapse/death; ${ }^{\mathrm{b}}$ event defined as relapse/death/secondary malignancies; 'event defined as relapse.

Abbreviations: MTHFR, methylenetetrahydrofolate reductase; SNP, single-nucleotide polymorphism; MTX, methotrexate; ALL, acute lymphoblastic leukemia; NHL, nonHodgkin Lymphoma; NA, no association between the SNP and outcome; +AS, SNP is associated to increased outcome; -AS, SNP is associated with decreased outcome; EFS, event free survival.

ALL. The majority of these studies does not find association or present opposite effect. As a result, MTHFR C677T and A1298C polymorphisms cannot be considered as toxicity or outcome markers for childhood ALL. Therefore, the efforts should be focused on other genes. For instance, interesting and robust results have been obtained in regards to transporter genes and MTX toxicity. In fact, Treviño et al ${ }^{40}$ performed a genome-wide association study in patients with ALL and found rs4149081 and rs11045879 in SLCO1B1 strongly associated for the first time with MTX clearance, and this association was widely confirmed by subsequent studies. ${ }^{11,39,41}$ As a result, other works have focused their interest on the analysis of polymorphism in MTX transporters, finding several SNPs in genes such as $S L C 19 A 1, A B C C 4$, or $A B C C 2$ also associated with MTX levels and other toxicities. ${ }^{42-44}$

Additionally, miRNA-related SNPs interfering with miRNA levels or function may lead to drug resistance/ sensitivity. Since miRNA expression can be exogenously controlled by blocking the expression of upregulated miRNAs or by restoring the expression of downregulated miRNAs, this field seems very promising in pharmacogenetics. Indeed, our group has detected 3 SNPs in miR-5189, miR-595, and miR-453 that might affect SLC46A1, SLC19A1, SLCO1A2, and $A B C C 4$ MTX transport genes regulation and could affect MTX levels in patients with pediatric B-ALL. ${ }^{45,46}$

\section{Disclosure}

The authors report no conflicts of interest in this work.

\section{References}

1. Koppen I, Hermans F, Kaspers G. Folate related gene polymorphisms and susceptibility to develop childhood acute lymphoblastic leukaemia. Br J Haematol. 2009;148:3-14.

2. Johnston WT, Lightfoot TJ, Simpson J, Roman E. Childhood cancer survival : a report from the United Kingdom Childhood Cancer Study. Cancer Epidemiol. 2010;34(6):659-666.

3. Pui C, Robison L, Look A. Acute lymphoblastic leukaemia. Lancet. 2008;371:1030-1043.

4. Gorlick R, Goker E, Trippett R, Waltham M, Banerjee D, Bertino J. Intrinsic and acquired resistance to methotrexate in acute leukemia. $N$ Engl J Med. 1996;335:1041-1048. 
5. Krajinovic M, Moghrabi A. Pharmacogenetics of methotrexate. Pharmacogenomics. 2004;5(7):819-834.

6. De Mattia E, Toffoli G. C677T and A1298C MTHFR polymorphisms, a challenge for antifolate and fluoropyrimidine-based therapy personalisation. Eur J Cancer. 2009;45(8):1333-1351.

7. Cheok M, Evans W. Acute lymphoblastic leukaemia: a model for the pharmacogenomics of cancer therapy. Nat Rev Cancer. 2006;6(2): $117-130$.

8. Frosst $\mathrm{P}$, Blom H, Milos R, et al. A candidate genetic risk factor for vascular disease: a common mutation in methylenetetrahydrofolate reductase. Nat Genet. 1995;10(1):111-113.

9. Weisberg I, Jacques P, Selhub J, et al. The 1298A/C polymorphism in methylenetetrahydrofolate reductase (MTHFR): in vitro expression and association with homocysteine. Atherosclerosis. 2001;156(2):409-415.

10. Niedzielska E, Węcławek-Tompol J, Matkowska-Kocjan A, Chybicka A The influence of genetic RFC1, MS and MTHFR polymorphisms on the risk of acute lymphoblastic leukemia relapse in children and the adverse effects of methotrexate. Adv Clin Exp Med. 2013;22(4):579-584. Available from: http://www.ncbi.nlm.nih.gov/pubmed/23986219.

11. Lopez-Lopez E, Martin-Guerrero I, Ballesteros J, et al. Polymorphisms of the SLCO1B1 gene predict methotrexate-related toxicity in childhood acute lymphoblastic leukemia. Pediatr Blood Cancer. 2011;57(4):612-619.

12. Lopez-Lopez E, Gutierrez-Camino A, Bilbao-Aldaiturriaga N, PombarGomez M, Martin-Guerrero I, Garcia-Orad A. Pharmacogenetics of childhood acute lymphoblastic leukemia. Pharmacogenomics. 2014;15(10):1383-1398

13. Esteller M. Aberrant DNA methylation as a cancer-inducing mechanism. Annu Rev Pharmacol Toxicol. 2005;45:629-656.

14. Abe M, Ohira M, Kaneda A, et al. CpG island methylator phenotype is a strong determinant of poor prognosis in neuroblastomas. Cancer Res. 2005;65(3):828-834.

15. Lopez-Lopez E, Martin-Guerrero I, Ballesteros J, Garcia-Orad A. A systematic review and meta-analysis of MTHFR polymorphisms in methotrexate toxicity prediction in pediatric acute lymphoblastic leukemia. Pharmacogenomics J. 2013;13(6):498-506.

16. Yang L, Hu X, Xu L. Impact of methylenetetrahydrofolate reductase (MTHFR) polymorphisms on methotrexate-induced toxicities in acute lymphoblastic leukemia: a meta-analysis. Tumor Biol. 2012;677 $1445-1454$.

17. Yanagimachi M, Goto H, Kaneko T, et al. Influence of pre-hydration and pharmacogenetics on plasma methotrexate concentration and renal dysfunction following high-dose methotrexate therapy. Int $J$ Hematol. 2013;98(6):702-707.

18. Torun YA, Patiroglu T, Ozdemir MA, Ozkul Y, Ekici A, Karakukcu M. Inherited prothrombotic risk factors in Turkish children with acute lymphoblastic leukemia: significance of concomitant genetic mutation. Clin Appl Thromb Hemost. 2012;18(2):218-221.

19. Sivaslioglu S, Gursel T, Kocak U, Kaya Z. The risk factors for thrombosis in children with acute lymphoblastic leukemia. Clin Appl Thromb Hemost. 2014;20(6):651-653.

20. Abdelaziz DH, Elhosseiny NM, Khaleel SA, Sabry NA, Attia AS, ElSayed MH. Association between combined presence of Hepatitis C Virus and polymorphisms in different genes with toxicities of methotrexate and 6-mercaptopurine in children with acute lymphoblastic leukemia. Pediatr Blood Cancer. 2016;63(9):1539-1545.

21. Tanaka Y, Manabe A, Nakadate H, et al. Methylenetetrahydrofolate reductase gene haplotypes affect toxicity during maintenance therapy for childhood acute lymphoblastic leukemia in Japanese patients. Leuk Lymphoma. 2014;55(5):1126-1131

22. Kaluzna E, Strauss E, Zajac-Spychala O, et al. Functional variants of gene encoding folate metabolizing enzyme and methotrexate-related toxicity in children with acute lymphoblastic leukemia. Eur J Pharmacol. 2015;769:93-99.

23. Karas Kuzelicki N, Milek M, Jazbec J, Mlinaric-Rascan I. 5,10-Methylenetetrahydrofolate reductase (MTHFR) low activity genotypes reduce the risk of relapse-related acute lymphoblastic leukemia (ALL). Leuk Res. 2009;33(10):1344-1348.
24. Ramírez-Pacheco A, Moreno-Guerrero S, Alamillo I, Medina-Sanson A, Lopez B, Moreno-Galvan M. Mexican childhood acute lymphoblastic leukemia: a pilot study of the MDR1 and MTHFR gene polymorphisms and their associations. Genet Test Mol biomrkers. 2016;20(10):597-602.

25. Haase R, Elsner K, Stiefel M, Mauz-Korholz C, Kramm C, Korholz D. High dose methotrexate treatment in childhood ALL : pilot study on the impact of the MTHFR 677C $>$ T and 1298A > C polymorphisms on MTX-related toxicity. Klin Pädiatrie. 2012;224(3):156-159.

26. Aráoz H, Aloi K, Foncuberta M, et al. Pharmacogenetic studies in children with acute lymphoblastic leukemia in Argentina Pharmacogenetic studies in children with acute lymphoblastic leukemia in Argentina. Leuk Lymphoma. 2015;56(5):1370-1378.

27. Zgheib N, Akra-Ismail M, Aridi C, et al. Genetic polymorphisms in candidate genes predict increased toxicity with methotrexate therapy in Lebanese children with acute lymphoblastic leukemia. Pharmacogenet Genomics. 2014;24(8):387-396.

28. Fukushima H, Fukushima T, Sakai A, et al. Polymorphisms of MTHFR associated with higher relapse/death ratio and delayed weekly MTX administration in pediatric lymphoid malignancies. Leuk Res Treatment. 2013;2013:1-9.

29. Imanishi H, Okamura N, Yagi M, et al. Genetic polymorphisms associated with adverse events and elimination of methotrexate in childhood acute lymphoblastic leukemia and malignant lymphoma. J Hum Genet. 2007;52(2):166-171.

30. Suzuki R, Fukushima H, Noguchi E, et al. Influence of SLCO1B1 polymorphism on maintenance therapy for childhood leukemia. Pediatr Int. 2015;57(4):572-577.

31. Moulik N, Kumar A, Agrawal S, Mahdi A, Kumar A. Effect of folate status and methylenetetrahydrofolate reductase genotypes on the complications and outcome of high dose methotrexate chemotherapy in north Indian children with acute lymphoblastic leukemia. Indian $J$ Med Paediatr Oncol. 2016;37(2):85-89.

32. Yazicioğlu B, Kaya Z, Ergun S, et al. Influence of folate-related gene polymorphisms on high-dose methotrexate-related toxicity and prognosis in Turkish children with Acute Lymphoblastic Leukemia. Turkish J Hematol. 2016:2-19.

33. Kantar M, Kosova B, Cetingul N, et al. Methylenetetrahydrofolate reductase $\mathrm{C} 677 \mathrm{~T}$ and $\mathrm{A} 1298 \mathrm{C}$ gene polymorphisms and therapy-related toxicity in children treated for acute lymphoblastic leukemia and nonHodgkin lymphoma. Leuk Lymphoma. 2009;50(6):912-917.

34. Karathanasis NV, Stiakaki E, Goulielmos GN, Kalmanti M. The role of the methylenetetrahydrofolate reductase 677 and 1298 polymorphisms in Cretan children with acute lymphoblastic leukemia. Genet Test Mol Biomarkers. 2011;15(1-2):5-10.

35. He H, Chen S, You H, et al. Association between methylenetetrahydrofolate reductase polymorphisms and the relapse of acute lymphoblastic leukemia: a meta-analysis. Pharmacogenomics J. 2014;14(5):432-438.

36. Ojha RP, Gurney JG. Methylenetetrahydrofolate reductase C677T and overall survival in pediatric acute lymphoblastic leukemia: a systematic review. Leuk Lymphoma. 2014;55(1):67-73.

37. D'Angelo V, Ramaglia M, Iannotta A, et al. Methotrexate toxicity and efficacy during the consolidation phase in paediatric acute lymphoblastic leukaemia and MTHFR polymorphisms as pharmacogenetic determinants. Cancer Chemother Pharmacol. 2011;68(5): 1339-1346.

38. Tantawy A, El-Bostany E, Adly A, et al. Methylene tetrahydrofolate reductase gene polymorphism in Egyptian children with acute lymphoblastic leukemia. Blood Coagul Fibrinolysis. 2010;21(1):28-34.

39. Radtke S, Zolk O, Renner B, et al. Germline genetic variations in methotrexate candidate genes are associated with pharmacokinetics, toxicity, and outcome in childhood acute lymphoblastic leukemia. Blood J. 2013;121(26):5145-5154.

40. Treviño L, Shimasaki N, Yang W, et al. Germline genetic variation in an organic anion transporter polypeptide associated with methotrexate pharmacokinetics and clinical effects. J Clin Oncol. 2009;27(35): 5972-5978.

41. Ramsey LB, Panetta JC, Smith C, et al. Genome-wide study of methotrexate clearance replicates SLCO1B1. Blood. 2013;121(6):898-904. 
42. Lopez-Lopez E, Ballesteros J, Pinan MA, et al. Polymorphisms in the methotrexate transport pathway: a new tool for MTX plasma level prediction in pediatric acute lymphoblastic leukemia. Pharmacogenet Genomics. 2013;23(2):53-61.

43. den Hoed MA, Lopez-Lopez E, te Winkel ML, et al. Genetic and metabolic determinants of methotrexate-induced mucositis in pediatric acute lymphoblastic leukemia. Pharmacogenomics $J$. 2015;15(3): $248-254$.

44. Gutierrez-Camino A, Lopez-Lopez E, Garcia-Orad A. SLC19A1 hot spot for MTX plasma concentration. Med Oncol. 2014;31(10):204.

45. Iparraguirre L, Gutierrez-Camino A, Umerez M, et al. MiR-pharmacogenetics of methotrexate in childhood B-cell acute lymphoblastic leukemia. Pharmacogenet Genomics. 2016;26(11):517-525.

46. Lopez-Lopez E, Gutierrez-Camino A, Pinan MA, et al. Pharmacogenetics of microRNAs and microRNAs biogenesis machinery in pediatric acute lymphoblastic leukemia. PLoS One. 2014;9(3):e91261.

47. Tsujimoto S, Tanaka F, Yanagimachi M, et al. Influence of ADORA2A gene polymorphism on leukoencephalopathy risk in MTX-treated pediatric patients affected by hematological malignancies. Pediatr Blood Cancer. 2016;63:1983-1989.
48. Wang S, Sun L, Zeng W, Wu W, Zhang G. Influence of genetic polymorphisms of FPGS, GGH, and MTHFR on serum methotrexate levels in Chinese children with acute lymphoblastic leukemia. Cancer Chemother Pharmacol. 2014;74:283-289.

49. de Deus D, de Lima E, Seabra Silva R, Leite E, Cartaxo Muniz M. Influence of methylenetetrahydrofolate reductase C677T, A1298C, and G80A polymorphisms on the survival of pediatric patients with acute lymphoblastic leukemia. Leuk Res Treatment. 2012;2012:1-6.

50. Kim H, Kang H, Kim H, et al. Pharmacogenetic analysis of pediatric patients with acute lymphoblastic leukemia: a possible association between survival rate and ITPA polymorphism. PLoS One. 2012;7(9):1-10

51. Leonardi D, Abbate M, Riccheri M, et al. Improving risk stratification of patients with childhood acute lymphoblastic leukemia: glutathioneS-transferases polymorphisms are associated with increased risk of relapse. Oncotarget. 2016;5:1-8.

52. Hoang P, Ambroise J, Dekairelle A, et al. Comparative pharmacogenetic analysis of risk polymorphisms in Caucasian and Vietnamese children with acute lymphoblastic leukemia: prediction of therapeutic outcome? Br J Clin Pharmacol. 2015;79(3):429-440.
Pharmacogenomics and Personalized Medicine

\section{Publish your work in this journal}

Pharmacogenomics and Personalized Medicine is an international, peerreviewed, open access journal characterizing the influence of genotype on pharmacology leading to the development of personalized treatment programs and individualized drug selection for improved safety, efficacy and sustainability. This journal is indexed on the American Chemical

\section{Dovepress}

Society's Chemical Abstracts Service (CAS). The manuscript management system is completely online and includes a very quick and fair peer-review system, which is all easy to use. Visit http://www.dovepress. $\mathrm{com} /$ testimonials.php to read real quotes from published authors. 